\title{
¿Se repetirá o no la paradoja David contra Goliat en el Acuerdo de Asociación Centroamérica - Unión Europea?
}

Luis Gustavo Murillo Orozco

Departamento de Economía, Facultad de Ciencias Económicas y Empresariales, Universidad Centroamericana. Correo electrónico: luisgmo@ns.uca.edu.ni

\section{Introducción}

Según una de las historias bíblicas del pueblo escogido de Dios, el tamaño individual no era importante ya que David siendo un persona joven, relativamente débil pero con una gran fe en el creador, venció al gigante filisteo Goliat. Sin embargo, muchos siglos después en un mundo globalizado, las acciones individualizadas basadas en la valentía y respaldadas por la fe ya no son eficaces pues el mercado exige cada vez más que grupos de países se integren y negocien como bloques por medio de sendos procesos de negociación y coordinación que irán conformando y consolidando mercados.

De estas circunstancias no se escapan los cinco países que conforman el Mercado Común Centroamericano (MCCA) y que se encuentran desde hace varias décadas intentando impulsar un proceso de integración económica que se ha acelerado en los últimos tiempos como producto de la firma del CAFTA y de la posible consolidación de un Acuerdo de Asociación con los países de la Unión Europea (UE). Estos dos esquemas de mercados globalizados le han exigido a Centroamérica (CA) tratar de funcionar como una región, al menos en el área aduanera.

El planteamiento anterior no se ha logrado porque la región centroamericana en su conjunto, y los países en particular, han asumido tantos compromisos que se diluyen entre los términos formales de los acuerdos y la falta de consenso a nivel interno de los países y como región. No obstante, en estos momentos representa una oportunidad el interés que ha mostrado la UE al tratar de establecer un Acuerdo de Asociación con $\mathrm{CA}$, tomando en cuenta que los europeos son los que han avanzado más firmemente un proceso de integración económica para el desarrollo y no tanto en el ámbito comercial. 


\section{CA y la UE: una analogía de David contra Goliat}

Como se puede observar en el Cuadro 1, son muy evidentes las diferencias que se dan entre CA y la UE en términos socioeconómicos. Del mismo modo, si nos centramos en estas cuestiones, apreciaremos cómo el diferencial existente en materia comercial tiene una razón de ser de mucha coherencia. Vemos cómo el bloque europeo tiene una superficie nueve veces mayor que la centroamericana y dispone de un mercado casi trece veces mayor.

Cuadro 1. Indicadores económicos y sociales de la UE y de CA. Año 2005. (en US\$ y porcentajes)

\begin{tabular}{|c|c|c|c|c|c|c|c|}
\hline Datos Generales & Guatemala & El Salvador & Honduras & Nicaragua & Costa Rica & Centroamérica & $\begin{array}{c}\text { Unión } \\
\text { Europea-25 }\end{array}$ \\
\hline $\begin{array}{l}\text { Tamaño (miles } \\
\text { km2) }\end{array}$ & 108,890 & 21,040 & 114,492 & 130,700 & 51,100 & 426,222 & $3.975,000$ \\
\hline $\begin{array}{l}\text { Población } \\
\text { (millones) }\end{array}$ & 12,700 & 6,900 & 7,300 & 5,500 & 4,300 & 36,700 & 463,523 \\
\hline $\begin{array}{l}\text { Densidad de } \\
\text { población }\end{array}$ & 116,631 & 327,947 & 63,760 & 42,081 & 84,149 & 86,105 & 116,610 \\
\hline IDH (año 2004) & 0,673 & 0,729 & 0,683 & 0,698 & 0,841 & 0,725 & 0,913 \\
\hline $\begin{array}{l}\text { Población bajo } \\
\text { umbral de pobreza } \\
\text { nacional (millones) }\end{array}$ & 7,137 & 3,333 & 3,869 & 2,635 & 0,946 & 17,920 & --- \\
\hline \% de la población & $56,20 \%$ & $48,30 \%$ & $53,00 \%$ & $47,90 \%$ & $22,00 \%$ & $48,83 \%$ & --- \\
\hline $\begin{array}{l}\text { PIB (miles de } \\
\text { millones US } \$ \text { ) }\end{array}$ & 28,174 & 16,242 & 7,711 & 4,689 & 19,381 & 76,197 & $13.036,618$ \\
\hline PIBpc & $2.218,394$ & $2.353,971$ & $1.056,274$ & 852,545 & $4.507,256$ & $2.076,213$ & $28.125,072$ \\
\hline Crecimiento PIB & 3,2 & 2,8 & 4,2 & 4,2 & 4,2 & 3,5 & 1,7 \\
\hline $\begin{array}{l}\text { Moneda (tipo de } \\
\text { cambio promedio } \\
\text { con US \$) }\end{array}$ & $\begin{array}{l}\text { Quetzal } \\
1 \$=7,63\end{array}$ & $\begin{array}{l}\text { Colón } \\
1 \$=8,75\end{array}$ & $\begin{array}{l}\text { Lempira } \\
1 \$=18,83\end{array}$ & $\begin{array}{l}\text { Córdoba } \\
1 \$=16,73\end{array}$ & $\begin{array}{l}\text { Colón } \\
1 \$=437,15\end{array}$ & --- & $\begin{array}{l}\text { Euro } \\
1 \$=1,24\end{array}$ \\
\hline $\begin{array}{l}\text { Exportaciones } \\
\text { bienes FOB (miles } \\
\text { de millones US \$) }\end{array}$ & 3,378 & 1,657 & 1,883 & 0,826 & 6,075 & 13,819 & $4.007,406$ \\
\hline $\begin{array}{l}\text { Importaciones } \\
\text { bienes CIF (miles } \\
\text { de millones US } \$ \text { ) }\end{array}$ & 8,816 & 5,380 & 4,566 & 2,491 & 8,034 & 29,287 & $4.056,370$ \\
\hline $\begin{array}{l}\text { Balanza comercial } \\
\text { (miles de millones } \\
\text { US \$) }\end{array}$ & $-5,437$ & $-3,723$ & $-2,683$ & $-1,665$ & $-1,959$ & $-15,467$ & $-48,964$ \\
\hline $\begin{array}{l}\text { Exportaciones / } \\
\text { habitante }\end{array}$ & 266,016 & 240,145 & 257,945 & 150,182 & $1.412,791$ & 376,550 & $8.645,539$ \\
\hline $\begin{array}{l}\text { Importaciones / } \\
\text { habitante }\end{array}$ & 694,142 & 779,710 & 625,479 & 452,909 & $1.868,372$ & 798,000 & $8.751,173$ \\
\hline $\begin{array}{l}\text { Grado de Apertura } \\
\text { comercial }\end{array}$ & $43,28 \%$ & $43,32 \%$ & $83,64 \%$ & $70,74 \%$ & $72,80 \%$ & $56,57 \%$ & $61,85 \%$ \\
\hline
\end{tabular}

Fuente: SIECA, Banco Mundial y PNUD (2005). 
Si a estos datos le añadimos que el porcentaje de población que vive bajo el umbral de la pobreza en CA -con bajo o nulo poder de compra- asciende a casi el $50 \%$ del total. Por tal razón podemos afirmar que el mercado real existente en el istmo es más reducido que el expuesto por meros datos estadísticos ${ }^{1}$. Ésta y otras muchas razones son las que hacen que la región del istmo se sitúe con un Índice de Desarrollo Humano de 0.725 -desarrollo humano medio- mientras que el bloque europeo disfrute de un Índice de 0.913.

En el marco de la producción nacional podemos derivar conclusiones similares, pues a pesar de que CA ha tenido niveles de crecimiento superiores a los europeos, como bloque las diferencias son muy marcadas. En este sentido, apreciamos cómo el PIB europeo es 161 veces el centroamericano, mientras que el PIB precios constantes es más de trece veces mayor. De un modo similar, en un plano estrictamente comercial observamos cómo las diferencias se agravan, pues a pesar de que la UE tiene un déficit por cuenta corriente mayor que el centroamericano, las exportaciones e importaciones de la primera son 290 y 138 veces las de la segunda, con unas exportaciones e importaciones por habitante notablemente superiores.

Adicionalmente, es interesante para el análisis hacer mención de que la economía europea ostenta un grado de apertura comercial mayor que el centroamericano, a pesar de que el del istmo supera el $56 \%$.

En definitiva, podemos afirmar que al comparar los principales indicadores económicos, demográficos, sociales y comerciales, las diferencias entre ambas regiones son muy significativas. Consecuentemente, en el contexto internacional, la UE se encuentra dentro de los denominados países desarrollados, mientras que CA es incluida dentro de los países en desarrollo en el contexto multilateral, y como economía pequeña, en el marco de un mercado hemisférico como es el ALCA.

En el terreno productivo, el istmo arrastra una evidente dependencia de la exportación de bienes primarios, fundamentalmente bienes de exportación tradicional, mientras que la UE dispone de una estructura productiva altamente industrializada y competitiva. Este hecho otorga a la segunda grandes ventajas comparativas y competitivas, fundamentalmente en el ámbito tecnológico, de capital humano y de factores productivos. Es decir, nos encontramos con dos economías muy disímiles y con grandes diferencias en prácticamente todos los aspectos.

\section{Significado del Acuerdo de Asociación CA vs UE}

En principio, el Acuerdo de Asociación es el establecimiento de compromisos mutuos concertados entre dos espacios de integración económica (CA vs UE) cuya base se sustenta en tres áreas complementarias entre sí.

1. Diálogo político

2. Cooperación

3. Establecimiento de una Zona de Libre Comercio entre las dos regiones 
El componente diálogo político persigue establecer mecanismos institucionalizados para promover una discusión e intercambio de información (en diferentes instancias) entre la UE y CA sobre cuestiones bilaterales y regionales de interés común, lo que podría permitir la adopción de posiciones conjuntas en temas de trascendencia internacional. A través de estos mecanismos se busca promover una serie de valores comunes entre ambas regiones tales como el respeto a los principios democráticos y los derechos humanos fundamentales, la protección del medio ambiente y el fortalecimiento del Estado de Derecho.

Respecto al componente de cooperación se busca ir más allá de la ayuda financiera que fluye de la UE hacia CA, para abarcar objetivos más contundentes que busquen promover una cohesión social e integración regional. Ésta debe estar orientada a la identificación de mecanismos concretos a través de los cuales ambas regiones puedan alcanzar los objetivos identificados tanto en el componente de diálogo político como en el componente comercial.

En el área comercial el Acuerdo de Asociación implicaría el establecimiento de una Zona de Libre Comercio entre CA y la UE. Es importante remarcar que CA ha mantenido por mucho tiempo lazos económicos estrechos con Europa que se han visto beneficiados por el Sistema Generalizado de Preferencias (SGP) que permite que muchos de los productos centroamericanos ingresen en ese mercado sin pagar aranceles o con aranceles preferenciales. A pesar de ello, otra cantidad significativa de bienes en los que CA tiene ventaja competitiva han estado excluidos de esa iniciativa, lo que ha promovido que desde hace varios años los países de la región hayan promovido avanzar en la profundización de la relación comercial a través de la suscripción de un Acuerdo de Libre Comercio.

Como puede verse, el Acuerdo de Asociación entre CA y la UE es una suerte de acercamiento entre dos regiones que desde los años cincuenta ha impulsado procesos de integración económica. No obstante, los europeos han avanzado más rápidamente que nosotros los centroamericanos que nos hemos acercado más al simple modelo de TLC impulsado por Estados Unidos. Por tal razón, el interés preliminar que tienen los países de la UE en la actualidad refleja bajas expectativas en materia comercial, dándole más peso a las áreas políticas, fortalecimiento democrático, utilizando las ventajas reales de ser exportadores netos de cooperación para el desarrollo en al menos cuatro de los cinco países que conformamos el istmo centroamericano.

\section{Antecedentes del Acuerdo de Asociación entre CA y la UE}

Las negociaciones de un Acuerdo de Asociación entre la UE y CA no son una decisión de última hora, sino una nueva etapa de un largo proceso que se remonta a más de tres décadas de diálogo y preparación, y que cobra una mayor dinámica en los años noventa. Asimismo, estas negociaciones se enmarcan en el objetivo de la UE y de países de CA (al igual que del resto de países de América Latina y el Caribe) de fortalecer sus relaciones económicas, políticas y de cooperación así como de establecer una Zona de Libre Comercio para el año 2010.

La región Centroamericana y la UE tienen un rico historial de relaciones políticas, económicas, institucionales y de cooperación. En la década de los años setenta esta relación 
se circunscribió al ámbito comercial a través del SGP, en los ochenta tomó importancia la cooperación para el desarrollo y la construcción de espacios de diálogo, especialmente en la región centroamericana, y en los noventa se cimentó la construcción de un conjunto de mecanismos de cooperación industrial, científica y tecnológica y de marcos de cooperación más avanzados.

El principal foro que enmarca la relación entre la UE y los países centroamericanos es el que se ha denominado "diálogo de San José”, que es esencialmente un foro de discusión política iniciado en 1984 y que fue en su origen dirigido a contribuir a la solución de conflictos, la democratización y el desarrollo de CA. El diálogo se ha renovado varias veces, ampliando su cobertura e incluyendo aspectos de integración regional, desastres naturales y ambientales, relaciones biregionales y concertación política en temas internacionales de interés común y en particular tras la decisión, emanada de la II Cumbre de Jefes de Estado y de Gobierno de la UE y América Latina y Caribe (ALC), celebrada en Madrid el 17 de mayo de 2002, de negociar un Acuerdo de Diálogo Político y de Cooperación.

En esta Cumbre se dejó claro que la integración regional es una de las prioridades de la agenda común, considerando que la Unión Aduanera debe ser un aspecto fundamental del proceso de integración. De esta forma se lograría crear mercados de mayor magnitud, favoreciendo así las posibilidades comerciales y el espacio para la inversión extranjera, así como una mayor capacidad de negociación en el escenario internacional.

Los Jefes de Estado y de Gobierno de CA y la UE se reunieron en Guadalajara, México el 29 de mayo de 2004. Acordaron poner en marcha un proceso que conduciera a un Acuerdo de Asociación cuyas negociaciones empezarían después de la actual fase de evaluación conjunta del proceso de integración económica de CA.

En este proceso de valoración se consideran como indicadores principales el marco institucional de la integración económica, la Unión Aduanera, el marco reglamentario comercial y la reducción de los obstáculos no arancelarios al comercio intraregional. El 7 y 8 de noviembre de 2005 se realizó la III reunión del Grupo de Trabajo Conjunto Ad-Hoc UE - CA en el marco de la fase de valoración conjunta del proceso de integración económica regional centroamericana. Panamá expresó su voluntad de integrarse con CA a través de TLC. Ambas partes acordaron revisar antes de la Cumbre de Viena de mayo de 2006 los avances adicionales de la integración económica regional en CA, con vistas a una decisión sobre el inicio de las negociaciones de un Acuerdo de Asociación entre ambas regiones.

El proceso de valoración, sin embargo, ha dejado mucho que desear pues aunque se reconoce en el diálogo de San José que la Unión Aduanera y el acceso a nuevos mercados no son condiciones suficientes para impulsar el desarrollo de los países centroamericanos, y que se requieren transformaciones de diferente índole -tanto económico como político y socialque generen una plataforma adecuada para el desarrollo, muchos de estos elementos no están presentes y se puede considerar que los factores de índole económico y comercial cobran predominancia. 
Es hasta marzo de 2006 que los gobiernos centroamericanos acordaron en la Declaración de Panamá trabajar contundentemente para asegurar que en la Cumbre de Viena se anunciase oficialmente la decisión de iniciar las negociaciones de un Acuerdo de Asociación que incluya una Zona de Libre Comercio.

\section{Evolución y resultados del Acuerdo de Asociación entre CA y la UE}

El Acuerdo de Asociación entre CA y la UE es un proceso relativamente reciente pero sumamente dinámico, lo que se refleja en la celebración de una fuerte cantidad de rondas tanto de negociación como de coordinación en un período muy corto (2007 - 2008).

Cuadro 2. Rondas de negociación entre la UE y CA de cara al Acuerdo de Asociación

\begin{tabular}{|c|c|c|}
\hline Ronda & Lugar & Fechas \\
\hline I Ronda & San José, Costa Rica & 22 al 26 de octubre de 2007 \\
\hline II Ronda & Bruselas, Bélgica & 25 al 29 de febrero de 2008 \\
\hline III Ronda & El Salvador & 14 al 18 de abril de 2008 \\
\hline IV Ronda & Bruselas, Bélgica & 14 al 18 de julio de 2008 \\
\hline V Ronda & Guatemala & 6 al 10 de octubre de 2008 \\
\hline VI Ronda & Bruselas, Bélgica & 1 al 5 de diciembre de 2008 \\
\hline
\end{tabular}

Cuadro 3. Rondas de coordinación entre la UE y CA de cara al Acuerdo de Asociación

\begin{tabular}{|c|c|c|}
\hline Ronda & Lugar & Fechas \\
\hline VIII Ronda & San José, Costa Rica & 21 al 25 de enero de 2008 \\
\hline IX Ronda & San José, Costa Rica & 11 al 15 de febrero de 2008 \\
\hline X Ronda & San Salvador, El Salvador & 24 al 28 marzo de 2008 \\
\hline XI Ronda & San Salvador, El Salvador & 26 al 30 de mayo de 2008 \\
\hline
\end{tabular}

A continuación se puntualizan algunos elementos importantes generados en las rondas de negociación:

I Ronda: Permitió generar una discusión conceptual sobre las perspectivas de ambas regiones, CA y la UE, en relación con los componentes de este acuerdo -político, cooperación y comercial- y aclarar los intereses de ambas partes.

Para este primer encuentro, el equipo negociador centroamericano se propuso de antemano tres objetivos fundamentales:

a. Conocer e interactuar directamente con el equipo de negociación de la UE -que había sufrido importantes cambios en el mes inmediatamente anterior a la celebración de la I Ronda. Por ello, la ronda de lanzamiento sirvió para que los equipos negociadores de 
CA y la UE se conocieran y establecieran una relación de comunicación directa, lo que constituye una variable muy importante en procesos complejos de negociación.

b. Lograr acordar con la contraparte de la UE una metodología de trabajo para desarrollar las negociaciones en cada uno de los tres componentes del Acuerdo de Asociación.

c. Aprovechar la ocasión para intercambiar, de una manera general, puntos de vista sobre los objetivos que cada región visualiza para cada uno de los tres componentes del Acuerdo.

El recuento de la I Ronda fue positivo y es posible afirmar que los objetivos que el equipo centroamericano se había planteado fueron alcanzados. En efecto, CA logró mantener y explicar una posición articulada como región y se acordó un plan de trabajo para cada componente del Acuerdo. En este sentido, tanto la UE como CA acordaron pasar de un ejercicio de discusión conceptual, hacia el inicio de una negociación sustantiva de cara a la II Ronda.

II Ronda: Se basó en el intercambio de propuestas y contrapropuestas de las regiones sobre los diferentes temas. Las partes acordaron utilizar como base, para los componentes de diálogo político y cooperación, el texto del Acuerdo de Diálogo Político y Cooperación que negociaron en 2003. Para el componente comercial acordaron utilizar como guía el Acuerdo de Asociación de la UE con Chile, adaptando dicho texto a las realidades de esta relación.

Con el objeto de concertar las posiciones que CA llevaría a la II Ronda, los países del istmo realizaron cuatro rondas de coordinación centroamericana. De estas rondas de coordinación cada país elaboró una lista de preguntas y/o comentarios generales e intercambio de información entre las partes que sirvieron de base para la elaboración de la contrapropuesta regional a la UE en las tres áreas temáticas del Acuerdo.

Esta Ronda podría caracterizarse como de "posicionamiento" de los temas de interés para ambas regiones. En particular, el objetivo de los países centroamericanos fue el de presentar propuestas concretas de texto en cada uno de los pilares del Acuerdo con el fin de que la UE pudiera comprender plenamente los intereses de la región en el proceso y reaccionar a los mismos en las etapas posteriores de la negociación.

III Ronda: Previo a esta ronda se realizaron reuniones de coordinación centroamericana para la discusión y presentación de las ofertas de acceso a mercados y servicios, así como la preparación de contrapropuestas de texto en cada uno de los temas de la negociación.

Esta Ronda fue particularmente importante porque en ella se dieron los primeros avances normativos y fue el inicio de la discusión sobre acceso a mercados de bienes. La región centroamericana continuó abogando en sus contrapropuestas por el reconocimiento explícito del principio de asimetría como punto focal de esta negociación. Asimismo, permitió transmitir a los negociadores europeos algunos mensajes importantes en relación con las aspiraciones de la región centroamericana para avanzar en los temas de la negociación, en particular en el tema de acceso a mercados y diálogo político. 
Ambas regiones tienen bastante claro el momento político que representa la Cumbre de Lima de mayo de 2008 para impulsar este proceso. En este escenario, esta III Ronda permitió llevar a la mesa temas de discusión que promoverán un avance más expedito en la negociación del Acuerdo.

En este contexto se realizó también una serie de actividades para la sociedad civil, entre ellas los cuartos adjuntos antes, durante y después de dicho evento. Los cuartos adjuntos se transmitieron en vivo por videoconferencia e Internet de manera simultánea. De esta manera toda persona interesada en mantenerse informada de los avances del proceso pudo hacerlo sin necesidad de trasladarse a El Salvador. Además de lo anterior, el equipo negociador regional participó en diversas actividades organizadas por la sociedad civil, entre ellas el foro organizado por el SICA.

Como puede verse, el proceso negociador entre CA y la UE en el marco del Acuerdo de Asociación no está acabado y de él se ciernen aún expectativas, esperanzas y dudas, ya que hasta el momento los negociadores que representan a cada una de las regiones están en estructuración de acercamiento y de ponerse de acuerdo con los mecanismos y las metodología que prevalecerán en el acuerdo definitivo. Sin embargo, algo positivo que se deriva del mismo es la mayor preocupación de los países centroamericanos en celebrar rondas de coordinación previas a las rondas de negociación a fin de buscar una posición consensuada como región, a pesar de que tal circunstancia es uno de los mayores retos que enfrenta la región centroamericana tomando en cuenta que desde la década de los años 60 ha buscado ese consenso en el marco del Mercado Común Centroamericano.

\section{Las condicionantes de la UE para la firma de un Acuerdo de Asociación con CA}

Uno de los requisitos que en su momento impuso la UE para avanzar en la negociación de un Acuerdo de Asociación con CA fue el avance de la Ronda de Doha en la $\mathrm{OMC}^{1}$, para que una eventual Zona de Libre Comercio quedara de conformidad con estos acuerdos.

El requisito de avanzar en la OMC se explicaba dado que la UE es un bloque comercial que esperaba muchos cambios en la Ronda de Doha a su favor. Además, en el tema agrícola y en el conflicto bananero, la UE y varias partes centroamericanas tienen diferencias que superar.

El segundo requisito impuesto por la UE ha sido la profundización del proceso de integración centroamericano - un marco institucional que permita a CA negociar como bloque-la creación de una Unión Aduanera y la reducción de los obstáculos no arancelarios al comercio intraregional.

Estas condicionantes quedaron explícitas en la Declaración de Guadalajara² y hasta antes de la reunión ministerial de la OMC en Hong Kong, la UE las planteaba con firmeza. En la Cumbre de Viena la UE debía manifestar si los avances en la OMC -incluyendo los acuerdos de Hong Kong- y los avances en el proceso de integración centroamericana, podían ser interpretados como suficientes para cumplir con los requisitos. En esta Cumbre se llegó a la siguiente conclusión respecto a las condiciones planteadas por la UE: 
1. Primera condición: Avance satisfactorio de la Ronda de Doha. Desde 2002, la UE planteó que un Acuerdo de Asociación con CA estaría condicionado a las normas de la OMC y a que se diera un avance en la Ronda de Doha en cuanto a la liberalización del comercio de toda clase de bienes y servicios. Sin embargo, las negociaciones de la OMC concluyeron en un acuerdo desfavorable para los países del Sur.

Según Oxfam Internacional (Secretaría general Oxfam Internacional, Informe 2006), "La Conferencia Ministerial de la OMC celebrada en Hong Kong ha sido una oportunidad perdida para lograr un comercio más justo para los pobres de todo el mundo. Los países ricos han puesto sus intereses comerciales por encima de los de los países en desarrollo. Los pequeños avances logrados en agricultura quedan más que anulados por unos textos sobre servicios y aranceles industriales que van en contra del desarrollo".

Este "avance" en la Ronda de Doha significa un retroceso para los países en desarrollo. Sin embargo, para la UE es suficiente para considerar como superado un requisito para avanzar en un Acuerdo de Asociación con América Central.

Como dice el diputado europeo Salafranca (Salafranca y Neyra, 2005:225), "El Parlamento Europeo...recuerda al efecto que los escasos resultados de la Conferencia Ministerial de Hong Kong tornan irrelevante la condicionalidad OMC del actual mandato de negociación con MERCOSUR y más aún en relación con los futuros mandatos para las negociaciones con la Comunidad Andina y Centroamérica”.

2. Segunda condición (un avance en la integración Centroamericana): Esta condición es que CA avance en su proceso de integración regional y sea capaz de negociar como un solo bloque.

La Comisión Europea destaca que su "enfoque multilateral se completa con la negociación de Acuerdos de Asociación y de Libre Comercio Birregionales con las regiones que estén suficientemente integradas en el sector comercial (con el MERCOSUR y, llegado el caso, la Comunidad Andina, CA y los países del Caribe)" (Secretaría General de la Comunidad Andina 2006). El interés expreso de la UE es la creación de mercados más amplios y menos fragmentados, pues considera que las inversiones europeas a CA fluirían más libremente con la existencia de una Unión Aduanera, un marco reglamentario para el comercio y la reducción de obstáculos no arancelarios al comercio intraregional.

Por su parte, los gobiernos de países centroamericanos han insistido en su voluntad política de avanzar en una Unión Aduanera y medidas relacionadas, y se encuentran satisfechos con los avances alcanzados. No obstante, a pesar de que existe una valoración conjunta entre la UE y CA de este proceso de integración, y que ha sido recibido con "satisfacción" por las partes europeas y centroamericanas, parece que una decisión final por parte de la UE, en el sentido de aprobar los avances realizados en el proceso de integración centroamericana y poder empezar las negociaciones de un Acuerdo de Asociación, debe se ser anunciada de último momento. Adicionado a ello, a pesar de que hay una valoración positiva por parte de los gobiernos, algunas Organizaciones de la Sociedad Civil de CA se muestran más escépticas con respecto a los grados de avance de la integración centroamericana y han expuesto las siguientes preocupaciones (Coordinadora Civil, 2007): 
a. El avance real de una integración centroamericana, incluso en el plano comercial, es parcial. En cuanto a una Unión Aduanera aún no se han homologado 353 rubros (de los cuales 118 son agropecuarios). Aunque hay un avance considerable pues el $94 \%$ de rubros se van a armonizar, el 6\% restante son de lo más delicados.

b. Es preocupante que no haya una Política Agrícola Común centroamericana que sirva de contraparte a la europea. Es necesaria una voz ciudadana basada en grupos de productores a nivel regional que puedan defender sus intereses, de campesinos y de micro, pequeños y medianos empresarios. Asimismo, es necesario que exista una idea más clara de una ciudadanía regional.

c. Aunque existen desde los años 50 y 60 esfuerzos para llegar a una integración con una visión sistémica, y en los años 90 se dio una reedición de esos esfuerzos con la creación del Sistema de Integración Centroamericano (SICA) que incluiría aspectos de integración económicos, políticos, sociales, ambientales, culturales, etc., mucho del trabajo queda en declaraciones "maravillosas" pero no se traducen en algo concreto. Quedan en retórica.

d. Según el COMIECO (Comité de Ministros Económicos y de Comercio) se ha "erosionado" la integración misma pues se han afectado a las dos canastas de bienes y servicios (A y B) al salir de ellas algunos productos. Además, se da una serie de exoneraciones de impuestos y salvaguardas unilaterales.

e. Existen conflictos en los territorios por diferendos limítrofes, militarización de las fronteras, incumplimiento de acuerdos binacionales (construcción de carreteras y aduanas), y algunos conflictos de agua. Muchas comunidades piden "fuera fronteras" porque son marcadas artificialmente y afectan sus vínculos "naturales”, tanto para sus relaciones familiares como comerciales.

De acuerdo con algunos analistas, la viabilidad de la integración en el corto plazo es imposible y en la actualidad se trata más de una voluntad de llegar a la integración por factores exógenos, como la condicionalidad por parte de la UE, que por factores endógenos. De acuerdo con Organizaciones de la Sociedad Civil (Coordinadora Civil, 2007) “...las persistentes desigualdades económicas entre los países del Istmo, los conflictos territoriales y de inmigración, la divergencia de posturas y compromisos frente a las metas de la integración y la ejecución parcial de los acuerdos regionales, hacen que la región siga presentado un nivel de integración sumamente bajo" y demandan una integración "desde abajo, en lo social, en lo cultural, y que no sea un proyecto impuesto desde afuera. Una verdadera integración debe atender los problemas de desigualdad y las asimetrías internas".

A pesar de lo acordado en el diálogo de San José, el requisito de la UE actual consiste en una mayor integración centroamericana tan sólo en aspectos comerciales y económicos. Un proceso de integración más abarcador exigiría, además, las condiciones y recursos necesarios para su apuntalamiento.

\section{Intereses europeos en un Acuerdo de Asociación con CA}

El hecho de que la UE promueva la integración centroamericana como un requisito para la negociación de un Acuerdo de Asociación, parece indicar, desde el punto de vista económico, que la región no es atractiva como mercado y como captadora de Inversión Extranjera 
Directa (IED), si no que es vista en forma de mercado ampliado. Cada país en sí mismo es muy pequeño, pero la región como un todo es un poco más atractiva.

Desde el punto de vista de la IED pueden darse varias oportunidades. Una primera es la de tratar de que empresas europeas capten el mercado centroamericano de algunos bienes y servicios. Es lo que ha pasado, por ejemplo, en áreas como telecomunicaciones y energía, lo mismo que en el caso de la industria cervecera. La integración tiene sentido en este caso porque garantiza un mercado mayor para esas empresas que invertirían en cualquiera de los países de la región pero que podrían vender en todos.

Una segunda oportunidad se da en términos de captar otros mercados para los que los países de la región tienen ventajas negociadas y de experiencia. El caso más claro es el de llegar al mercado norteamericano. Podría ser el caso de empresas en la industria farmacéutica.

Una tercera opción es la de que empresas europeas se instalen en el país para exportar a Europa. Esta sería una estrategia de disminución de costos, especialmente los de mano de obra. Algunas empresas en servicios como call-centers siguen esta estrategia. Son generadoras netas de divisas.

Una cuarta variante más es la de empresas insertas en algunos servicios a nivel nacional pero que captan clientes a nivel internacional. El caso típico es el de empresas que invierten en el sector turismo.

En CA se ha dado espacio para todas las opciones. Así, por ejemplo, en Costa Rica los principales montos de IED europea se centraron en adquisiciones de empresas ya establecidas. Los casos más significativos se dieron en 2002 con la compra del 25\% de Florida Bebidas por Heineken de Holanda y en 2003 con la adquisición de la empresa de servicios Cormar por la estatal Correos de Alemania. Pero también se han dado inversiones en el sector turismo y recientemente en servicios como call-centers.

En Honduras los flujos de la IED se han dirigido a varias ramas de la actividad económica. La IED destinada a la industria y al comercio representó en el período 1993-2002 entre el 30\% y 50\% de la IED total. En los años 2001 y 2002 sobresale el aumento de IED en los sectores de telecomunicaciones y financiero, comportamiento explicado por la inyección de inversión extranjera en varios bancos del sistema, así como por la concesión de los aeropuertos y el auge de la telefonía móvil. Estas dos últimas industrias son casos típicos de inversiones que vienen dirigidas a captar el mercado nacional.

En el caso de El Salvador gran parte de la IED de origen europeo se ha canalizado a los sectores de telecomunicaciones y a otros servicios. Esto refleja la tendencia de hacer negocios en servicios que no son transables y que por tanto, las empresas extranjeras que quieran participar en tales negocios tienen que hacer IED. En El Salvador muchas de esas inversiones fueron mediante la adquisición de empresas privatizadas.

En Nicaragua también se han dado inversiones por parte de empresas europeas en el sector electricidad orientadas principalmente a captar el mercado nacional, como es el caso de 
Unión FENOSA, así como en el sector turístico representado por el consorcio hotelero de origen español Barceló Montelimar.

Parecido a lo que sucede en general en América Latina, gran parte de la explicación del crecimiento de las inversiones en CA está basada en las privatizaciones. Quizás Costa Rica sea la excepción. También hay una creciente tendencia de la IED de orientarse hacia el sector de servicios. En algunos sub sectores los servicios no son transables, por lo que la tendencia puede traducirse en problemas macro, ya que las empresas que invierten no generan sus propias divisas.

Hay que reflexionar también sobre en qué medida esos servicios están contribuyendo o no a una mayor eficiencia en las economías de la región. Un aspecto a rescatar es que la mayoría de desinversiones o flujos negativos se da en empresas de inversión europea. La realidad ha demostrado que la IED europea ha sido en promedio más propensa a generar transferencias hacia el exterior.

\section{El interés de CA en alcanzar un Acuerdo de Asociación con la UE}

El intercambio de bienes entre la UE y CA está caracterizado por el otorgamiento de una serie de beneficios unilaterales a las importaciones de los países latinoamericanos por parte de la UE. Éstos generalmente han sido mayores a los otorgados a otros bloques y países en desarrollo de Asia y América Latina (AL), pero menores que las que la UE le brinda a los países de Asia del Pacífico (los llamados Tigres Asiáticos). Esta situación se encuentra explicada por el abordaje que la UE practica con los países de América Latina.

Mediante un trato uniforme pero diferenciado, la UE ha privilegiado una relación más comercial y asociativa con Chile, el MERCOSUR y México, países con economías de ingresos per cápita mayores. Ha optado por la cooperación y las preferencias unilaterales en el caso de CA y la Comunidad Andina. El resultado sin embargo es que, a pesar de que es ampliamente aceptado el éxito del diálogo político, en particular su aporte a la solución del conflicto armado en CA en los noventa, y el significado de la cooperación europea hacia la región, las relaciones comerciales entre las partes no comparten el mismo optimismo.

Es desde los años setenta que la UE ha dado un acceso preferente a los países en desarrollo a través de su SGP. Adicionalmente, de 1991 a 2005, los países de la Comunidad Andina se beneficiaron con el SGP de apoyo a la lucha contra la producción y el tráfico de droga (SGP droga), que bajo el principio de responsabilidad compartida, brindó un mejor trato que el SGP a un mayor número de productos de exportación de esta región. Luego de que los países de CA lo demandaran, este régimen también les fue extendido. En 2005, a raíz de la expiración del SGP, e influenciado por un fallo de la OMC que condenó, inter alia, la forma de designar a los beneficiarios del mismo, la UE eliminó los SGP especiales -como el SGP droga- y estableció otro llamado "SGP ampliado" para los países que "promuevan el desarrollo sostenible y el buen gobierno" (Secretaría General de la Comunidad Andina 2005.)

A pesar de la complementariedad entre las economías europeas y latinoamericanas, y del acceso preferencial brindado por la UE a las exportaciones de bienes de CA, así como de 
la relevancia de la UE como socio comercial tanto por su tamaño como por ser el mayor importador mundial, la última década ha sido testigo de una constante pérdida de importancia en el comercio entre ambas regiones. En los casos en que el comercio ha aumentado, salvo situaciones excepcionales, ha sido a raíz de un aumento de las importaciones desde Europa que realizan los países de CA.

Cuadro 4. Balanza comercial de CA con la UE (en millones de dólares)

\begin{tabular}{|c|c|c|c|c|c|}
\hline & Año 2001 & Año 2002 & Año 2003 & Año 2004 & Año 2005 \\
\hline Exportaciones & 1386.39 & 1349.82 & 1927.34 & 1880.44 & 2173.03 \\
\hline Importaciones & 1678.58 & 2004.34 & 2635.71 & 2909.47 & 3254.55 \\
\hline Saldo & -292.19 & -654.52 & -908.37 & -1029.03 & -1081.52 \\
\hline
\end{tabular}

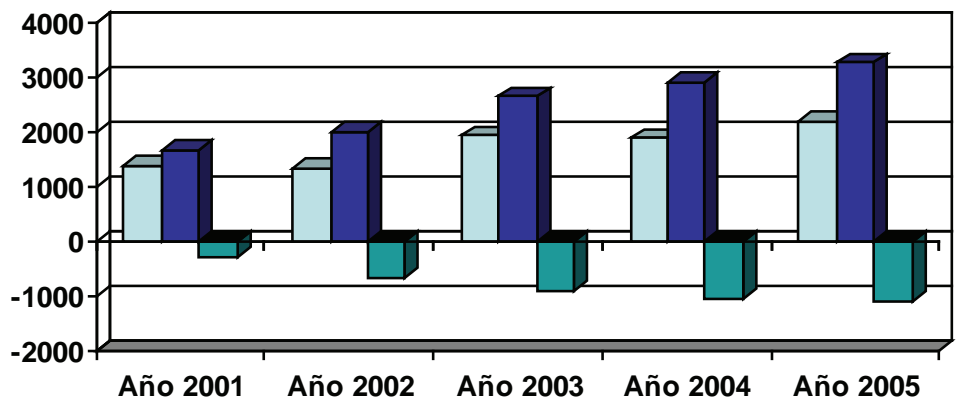

Ilustración 1. Balanza comercial de CA con la UE (en millones de dólares)

Si bien CA es un socio comercial marginal dentro del comercio de la UE (tomados conjuntamente CA y Panamá suman cerca del 0.4\% de las exportaciones y 0.3\% de las importaciones europeas), lo contrario no es cierto. La importancia de CA como socio comercial para la UE se deriva más bien del dinamismo de sus importaciones. En la década de los noventa, las exportaciones europeas hacia América Central crecieron más rápido que las destinadas a cualquier otra región en desarrollo.

Para el caso de CA, el comercio de bienes con la UE pasó de representar alrededor del 15\% a cerca del 10\% de 1994 a 2004, lo cual implica que la UE dejó de ser el segundo socio comercial, lugar ocupado actualmente por el comercio intraregional centroamericano. A pesar de que el saldo de la balanza comercial entre ambas regiones fue positivo para CA en los noventa, no está claro si esta situación se volverá a repetir dado que las importaciones desde Europa han aumentado mucho más rápido (5.9\% anualmente) que las exportaciones (0.7\% anualmente) en el período citado. Esto ha tenido como consecuencia la aparición de un amplio déficit comercial de CA respecto a la UE. 
Cuadro 5. Principales productos de exportación de CA hacia la UE

\begin{tabular}{|l|l|l|}
\hline Descripción* & Valor en euros & Part. \% \\
\hline 1 Café 582.925.129 30,0\% & & \\
\hline 2 Accesorios de máquina de la partida No 84.71 & 228.130 .841 & $11,8 \%$ \\
\hline 3 Bananas o plátanos, frescos o secos & 226.281 .585 & $11,7 \%$ \\
\hline 4 Piñas tropicales (ananás), frescas o secas & 170.831 .081 & $8,8 \%$ \\
\hline 5 Equipos eléctricos para amplificación de sonido & 87.010 .146 & $4,5 \%$ \\
\hline 6 Camarones, langostinos congelados & 78.797 .575 & $4,1 \%$ \\
\hline 7 Atunes, listados y bonitos & 59.792 .345 & $3,1 \%$ \\
\hline 8 Follaje, hojas, ramas frescos & 57.586 .560 & $3,0 \%$ \\
\hline 9 Melones frescos & 30.853 .037 & $1,6 \%$ \\
\hline 10 Las demás plantas vivas & 30.635 .195 & $1,6 \%$ \\
\hline 11 Minerales de cinc & 20.622 .398 & $1,1 \%$ \\
\hline 12 Compotas, jaleas y mermeladas & 19.594 .031 & $1,0 \%$ \\
\hline 13 Antenas y reflectores de antena de cualquier tipo & 17.881 .645 & $0,9 \%$ \\
\hline 14 Aceites de petróleo o mineral bituminoso & 16.650 .011 & $0,9 \%$ \\
\hline 15 Circuitos integrados monolíticos & 13.455 .409 & $0,7 \%$ \\
\hline 16 Jugo de piña tropical (ananá) & 13.219 .689 & $0,7 \%$ \\
\hline 17 Palmitos, preparados o conservados & 13.161 .979 & $0,7 \%$ \\
\hline 18 Jeringas, agujas, catéteres & 12.436 .564 & $0,6 \%$ \\
\hline 19 Alcohol etílico sin desnaturalizar & 10.706 .750 & $0,6 \%$ \\
\hline 20 Los demás jugos de piña tropical (ananá) & 10.655 .940 & $0,5 \%$ \\
\hline 21 Cacahuates (maníes) sin tostar & 9.809 .871 & $0,5 \%$ \\
\hline 22 Partes y accesorios de cámaras & 9.629 .048 & $0,5 \%$ \\
\hline 23 Interruptores, seccionadores y conmutadores & 8.650 .683 & $0,4 \%$ \\
\hline 24 Ron y demás aguardientes de caña & 8.607 .260 & $0,4 \%$ \\
\hline 25 Jugo de naranja sin congelar & 8.236 .460 & $0,4 \%$ \\
\hline
\end{tabular}

Fuente: SIECA 
Cuadro 6. Principales productos de importación de CA hacia la UE

\begin{tabular}{|c|c|c|}
\hline Descripción* & Valor en euros & Part. \% \\
\hline 1 Circuitos integrados digitales & 396.579 .879 & $13,6 \%$ \\
\hline 2 Medicamentos & 183.689 .121 & $6,3 \%$ \\
\hline 3 Aceites ligeros preparaciones de petróleo & 133.946 .658 & $4,6 \%$ \\
\hline 4 Vehículos con motor de émbolo alternativo & 60.510 .102 & $2,1 \%$ \\
\hline 5 Aparatos de telecomunicación & 49.959.216 & $1,7 \%$ \\
\hline $\begin{array}{l}\text { 6Aparatos emisores deradiotelefonía, radiotelegrafía, } \\
\text { radiodifusión o televisión, con aparato receptor } \\
\text { incorporado }\end{array}$ & 32.625 .246 & $1,1 \%$ \\
\hline 7 Fungicidas & 30.216 .469 & $1,0 \%$ \\
\hline 8 Placas y baldosas de cerámica & 29.939 .920 & $1,0 \%$ \\
\hline 9 Urea, incluso en disolución acuosa & 28.079 .476 & $1,0 \%$ \\
\hline 10 Aceites de petróleo & 27.765 .843 & $1,0 \%$ \\
\hline $\begin{array}{l}11 \text { Aparatos emisores de radiotelefonía, } \\
\text { radiotelegrafía, radiodifusión o televisión }\end{array}$ & 23.162 .049 & $0,8 \%$ \\
\hline 12 Productos laminados planos enrollados & 23.112 .846 & $0,8 \%$ \\
\hline 13 Partes de motores de las partidas No 84.07 ó 84.08 & 19.791 .723 & $0,7 \%$ \\
\hline 14 Los demás vehículos con motor de émbolo & 19.394 .954 & $0,7 \%$ \\
\hline 15 Sulfato de amonio & 18.160 .955 & $0,6 \%$ \\
\hline $\begin{array}{l}16 \text { Partes destinadas a las máquinas de las partidas } \\
85.01 \text { ó } 85.02\end{array}$ & 17.641 .254 & $0,6 \%$ \\
\hline 17 Aparatos de telefonía o telegrafía & 16.259 .599 & $0,6 \%$ \\
\hline $\begin{array}{l}18 \text { Tarjetas provistas de un circuito integrado } \\
\text { electrónico }\end{array}$ & 16.190 .746 & $0,6 \%$ \\
\hline 19 Whisky & 16.051 .452 & $0,6 \%$ \\
\hline $\begin{array}{l}20 \text { Partes de aparatos eléctricos de telefonía, } \\
\text { telegrafía con hilos }\end{array}$ & 15.901 .318 & $0,5 \%$ \\
\hline 21 Vehículos con motor de émbolo & 15.541 .434 & $0,5 \%$ \\
\hline
\end{tabular}

Fuente: SIECA (2006).

Dentro de las razones que explican la pérdida del dinamismo en el intercambio comercial comentado, podríamos considerar en primer lugar la composición de los flujos comerciales entre ambas regiones. CA (con la excepción de Costa Rica) exporta hacia la UE primordialmente bienes primarios, mientras que importa bienes manufacturados (los bienes agroindustriales -contenidos en las primeras cuatro secciones del Sistema Armonizadorepresentan el 70\% de las exportaciones centroamericanas). Dado el menor dinamismo en 
el crecimiento de la demanda de los bienes primarios ante cambios en el ingreso, es de esperar que si esta estructura de intercambio comercial se mantiene, las exportaciones de la UE hacia CA crecerán más rápido que al inverso.

En segundo lugar, la estrategia comercial seguida por ambas regiones en los últimos años ha propiciado la celebración de acuerdos comerciales con socios "naturales". De esta manera el Sistema de Integración Centroamericano se ha expandido de diversas formas incluyendo a países como Panamá y la República Dominicana. Además se han llevado a cabo Acuerdos Comerciales con vecinos o con economías complementarias como Canadá, Chile, México y los EEUU. Por su parte la UE ha hecho lo propio y en 2003 amplió su membresía a diez países de Europa Occidental, además de la firma de Acuerdos de Asociación con otros países.

En tercer lugar, barreras comerciales en el mercado de la UE han persistido, mientras que en general los países de América Latina han profundizado un proceso de apertura unilateral iniciado en los noventa. Dentro de las barreras comerciales se pueden citar crestas arancelarias, contingentes y altos aranceles promedio en productos de exportación clave para CA como los agrícolas. También persisten barreras no arancelarias, escalamiento arancelario, y el otorgamiento de ayudas internas y subsidios a la exportación que no sólo afectan las exportaciones centroamericanas en el mercado europeo sino en el de terceros.

En cuarto lugar debemos señalar la incapacidad de los gobiernos y de los sectores privados de los países de CA de enfrentar un clima adverso y realizar los cambios necesarios a tiempo para aprovechar las oportunidades y enfrentar los retos que todo proceso de apertura y desarrollo implica. La mejor muestra de ello es el caso de los países del sudeste asiático de reciente industrialización, quienes a pesar de partir de un nivel de desarrollo similar al centroamericano a mediados del siglo pasado y gozar de menores preferencias en el mercado de la UE, actualmente gozan de un mejor nivel de vida que CA, y han ampliado su intercambio comercial con la UE.

A este respecto cabe apuntar que diversos análisis han señalado la falta de iniciativa y desarrollo empresarial del sector privado centroamericano, lo cual incide negativamente en su desempeño comercial en el mercado mundial. Esto además se ve afectado por un entorno competitivo poco favorable dadas las carencias en infraestructura para la exportación, un entorno macroeconómico inestable, mercados ineficientes, ausencia de sistemas nacionales de innovación y escasa calificación de la mano de obra (excepto en Costa Rica).

Es precisamente en el tema de las barreras comerciales donde los países de CA buscaron lograr mayores concesiones por parte de la UE a través de una Zona de Libre Comercio. Sin embargo, las perspectivas no son muy halagüeñas si tomamos en cuenta la poca ambición de las ofertas de liberalización agrícola que la UE ha mostrado en las negociaciones bajo la Ronda de Doha y a nivel regional con el MERCOSUR.

Incluso en bienes en los que no presenta ventajas comparativas ni altos niveles de producción para los europeos -como el banano- el proteccionismo se ha mantenido. Unido a esto, el tema de la necesaria reforma a la Política Agrícola Común, por ser financieramente insostenible y causar roces con sus socios comerciales, no ha avanzado al ritmo esperado. Estos elementos 
parecen indicar que en temas clave para los países de CA, la UE se encuentra actualmente muy cerca de las "líneas rojas" y no está claro cuánto más está dispuesta a ceder o cuál será el precio que sus socios tendrán que pagar para mover posiciones de negociación con un alto margen de diferencia.

\section{Conclusiones}

- El Acuerdo de Asociación Comercial CA - UE está iniciando, razón por la cual se cierne sobre él una serie de expectativas, esperanzas y retos por parte de la región Centroamericana.

- Desde el punto de vista de la naturaleza del comercio entre la región centroamericana y la europea se observa una asimetría desfavorable al istmo centroamericano por cuanto las exportaciones hacia la UE son en su mayoría bienes primarios mientras que las exportaciones de Europa hacia CA son mayoritariamente productos manufacturados y posicionamiento de inversión.

- Un avance de este proceso de negociación con Europa ha sido la celebración de rondas de negociación de coordinación a fin de que la región centroamericana busque un consenso.

- Los intereses comerciales de Europa para la firma de un Acuerdo de Asociación con CA tienen menos intensidad que la parte política y de cooperación para el desarrollo, no así de CA hacia Europa.

\section{Notas}

1. Hay que añadir que la población indígena que habita en Centroamérica constituye aproximadamente el $25 \%$ de la población total del istmo. Esta población es víctima de los más altos niveles de segregación y exclusión y generalmente no entra dentro de los circuitos comerciales al no ser considerada como cliente potencial.

2 La OMC en el organismo internacional que sustituyo al antiguo GATT cuyo origen se remonta al año 1947.

3 Los Jefes de Estado y de Gobierno de Centroamérica y la Unión Europea se reunieron en Guadalajara, México el 29 de mayo de 2004. Acordaron poner en marcha un proceso que conduzca a un Acuerdo de Asociación cuyas negociaciones empezarían después de la actual fase de evaluación conjunta del proceso de integración económica de Centroamérica.

\section{Referencias bibliográficas}

CAMARERO, M. \& TAMARIT, C. R. (2006) La Unión Europea y las Américas: consecuencias del establecimiento de un acuerdo de asociación interregional entre la UE y Mercosur. Valencia: Universitat Jaume I y Universitat de Valencia.

COMISIÓN EUROPEA (2007) Estructura de negociación y coordinación del Acuerdo de Asociación Centroamérica - Unión Europea. Grupo de negociación.

COMISIÓN EUROPEA \& SIECA (2007) Informes de la I, II y III Ronda de negociación.

COORDINADORA CIVIL (2007). Publicaciones. Disponible en: www.cc.org.ni. Consultado: septiembre de 2008.

FUNDACIÓNNACIONALPARAEL DESARROLLO(FUNDE) \&INICIATIVAMESOAMERICANA DE COMERCIO, INTEGRACIÓN Y DESARROLLO (CID) (2006) Análisis y propuestas ante el Acuerdo de Asociación y Libre Comercio entre la Unión Europea y Centroamérica. San Salvador: FUNDE. 
HERNÁNDEZ GONZÁLEZ, G. \& OROZCO, J. (2005) Hacia un Acuerdo de Asociación entre Centroamérica y la Unión Europea ¿̇Un instrumento para el desarrollo y los derechos humanos o un CAFTA II? San Salvador.

SALAFRANCA SÁNCHEZ, F. \& NEYRA, J. I. (2005) Proyecto de Informe sobre una Asociación reforzada entre la Unión Europea y América Latina, Comisión de Asuntos Exteriores, Madrid: Parlamento Europeo, 19.1.2005. Provisional 2005/2241 (INI).

SECRETARÍA GENERAL DE LA COMUNIDAD ANDINA (2005). Disponible en: www. comunidadandina.org Consultado: septiembre de 2008.

SECRETARÍA GENERAL DE LA COMUNIDAD ANDINA (2006). Disponible en: www. comunidadandina.org Consultado: septiembre de 2008.

SECRETARÍA GENERAL OXFAM INTERNACIONAL (2006) Informe 2006. Londres: OXFAM SIECA, Informe de avance del Acuerdo de Asociación con Centroamérica 2006.

VÁZQUEZ VICENTE, G. (2006) Un Acuerdo de Asociación económica Unión EuropeaCentroamérica: oportunidades y desafíos para el istmo Centroamericano. Madrid. 